\title{
ANALISIS PERFORMA ENGINE MARCHETTI SF 260
}

\author{
Bismil Rabeta \\ Prodi Teknik Aeronautika, Fakultas Teknologi Kedirgantaraan, Universitas Suryadarma \\ Komplek Bandara Halim Perdanakusuma, Jakarta 13610, Indonesia \\ Corresponding Author : bismilrabeta@yahoo.co.id
}

\begin{abstract}
Abstrak - Universitas Dirgantara Marsekal Suryadarma (Unsurya) adalah Universitas yang bergerak dibidang teknologi dirgantara yang berupaya untuk memberikan kontribusi dan informasi terkait dengan teknologi penerbangan. Adapun fasilitas yang dimiliki Unsurya salah satunya adalah pesawat marchetti SF-260 yang digunakan sebagai fasilitas praktek untuk pelaksanaan ground run-up engine test. Selama pesawat ini ada di Unsurya, belum pernah ada yang mencoba untuk menganalisi performa engine pesawat tersebut. Oleh karena itu pada penelitian ini dilakukan analisis performa engine pesawat marchetti SF-260 dengan menggunakan engine Lycoming O-540 E4A5 untuk mengetahui torsi engine, daya mesin dan efisiensi mekanik yang divariasikan dengan ketinggian $10.000 \mathrm{ft}, 15.000 \mathrm{ft}$ dan $20.000 \mathrm{ft}$ pada saat terbang jelajah. Dari hasil analisis didapatkan bahwasanya nilai tertinggi pada torsi yaitu 480,24 Nm, daya mesin 182 BHP dan efisiensi mekanik 42,83\% yang didapat pada ketinggian $10.000 \mathrm{ft}$.
\end{abstract}

Kata Kunci: Pesawat Marchetti SF-260, Engine Lycoming SF-260, Torsi, Daya mesin dan efisiensi mekanik

Abstract - The Aerospace Air Marshal Surydarma University (Unsurya) is a college of movement in aerospace technology that attempts to contribute and information related to aviation technology. One of the facilities owned by Unsurya is the Marchetti SF-260 aircraft which is used as a practice facility for implementing ground run-up engine tests. As long as this aircraft is in Unsurya, no one has ever tried to analyze the engine's performance. Therefore in this study do an analysis of the performance of the marchetti aircraft SF-260 was carried out using the Lycoming O-540 E4A5 engine to determine engine torque, engine power and mechanical efficiency varied by cruising altitude. From the results of the analysis it was found that the highest value at torque was $480.24 \mathrm{Nm}$, engine power $182 \mathrm{BHP}$ and mechanical efficiency $42.83 \%$ obtained at an altitude of 10,000 ft.

Keywords: Marchetti SF-260, Lycoming SF-260, Torque, Power engine and mechanical efficiency 


\section{PENDAHULUAN}

Universitas Dirgantara Marsekal Suryadarma merupakan Universitas yang bergerak dibidang teknologi kedirgantaraan yang mempunyai komitmen untuk memberikan kontribusi dan informasi didunia penerbangan. Adapun fasilitas yang ada di Unsurya untuk kegiatan pelaksanakan pendidikan yaitu pesawat CASA-212 yang digunakan untuk praktek aircraft structure, aircraft system dan gas turbine engine, sedangkan untuk praktek ground run-up engine menggunakan pesawat marchetti SF-260 dimana pesawat ini masih dapat beroperasi saat didarat (ground) dan dapat beroperasi pada putaran penuh atau maksimum RPM namun statusnya sudah tidak layak terbang (grounded). Data-data umum yang pada pesawat yang ada di Unsurya tersedia melalui aircraft maintenance manual (AMM) ataupun EMM (Engine Maintenance Manual) dan EOM (Engine Overhaul Manual). Namun data-data spesifik seperti performa pesawat dan performa engine secara detil memang tidak ada di AMM, EMM maupun EOM. Sehingga pada penelitian ini dilakukan analisis performa engine Lycoming 0-540 E4A5 dengan variasi ketinggian yaitu $10.000 \mathrm{ft}$, $15.000 \mathrm{ft}$ dan $20.000 \mathrm{ft}$ pada saat terbang jelajah dengan menggunakan metode analitik. Adapun hasil analisis yang ingin didapatkan adalah torsi mesin, daya mesin dan efisiensi mekanik dari mesin Lycoming O-540 E4A5.

\section{METODE PENELITIAN}

\subsection{Landasan Teori}

Untuk melakukan analisis performa engine Lycoming O-540 E4A5, maka digunakan literature atau referensi yang valid sebelum dilakukan perhitungan secara bertahap. Adapun persamaan yang digunakan untuk mencari performa engine Lycoming $0-540$ E4A5 sebagai berikut :

\subsubsection{Volume Langkah \& Volume ruang bakar}

Volume

langkah

(piston displacement) adalah jumlah volume dari TMA dan TMB (untuk mesin yang memiliki cylinder lebih dari satu, dipakai istilah total displacement ). Volume ruang bakar adalah volume yang berada tepat diatas piston pada saat posisi piston di TMA yang berfungsi sebagai tempat pembakaran bahan bakar yang telah di kompresi oleh piston ${ }^{[1]}$ :

Untuk satu silinder :

$V_{d}=\left(\frac{\pi}{4}\right) B^{2} \cdot S$

Untuk volume langkah dengan jumlah

silinder lebih dari satu

$V_{d}=\left(\frac{\pi}{4}\right) B^{2} \cdot S . N c$

Volume ruang bakar :

$V_{s}=V_{d}+V_{c}$

\subsubsection{Perbandingan Kompresi}

Perbandingan kompresi $\left(r_{c}\right)$ adalah perbandingan volume ruang bakar saat piston berada pada titik mati bawah (TMB) dengan volume ruang bakar pada saat piston berada pada titik mati atas (TMA) ${ }^{[1]}$ :

Kompresi rasio :

$r_{c}=\frac{\left(V_{c}+V_{d}\right)}{V_{c}}$

\subsubsection{Perhitungan Siklus Ideal Otto (Siklus Volume Konstan)}

Siklus Otto ideal adalah siklus ideal untuk engine spark ignition, nama itu diberikan setelah Nikolaus A.Otto berhasil membuat mesin 4 langkah di Jerman pada tahun 1876. Untuk menggambar siklus ideal ini di buatkan lah diagram P-V dan T-S. Agar lebih mudah memahami diagram P-V dan T-S, maka dilakukan terlebih dahulu idealisasi. Proses yang terjadi sebenarnya berbeda dengan proses ideal[ ${ }^{[6]}$. Beberapa idealisasi pada siklus ideal antara lain :

- Fluida kerja dalam silinder adalah udara, dianggap gas ideal dengan konstanta kalor tetap.

- Proses kompresi dan ekspansi berlansung secara isentropic.

- Proses pembakaran dianggap sebagai proses pemanasan fluida kerja. 
- Pada akhir proses ekspansi, yaitu pada saat torak mencapai TMB, fluida kerja didinginkan sehingga tekanan dan temperatur turun mencapai tekanan dan temperatur atmosfer.

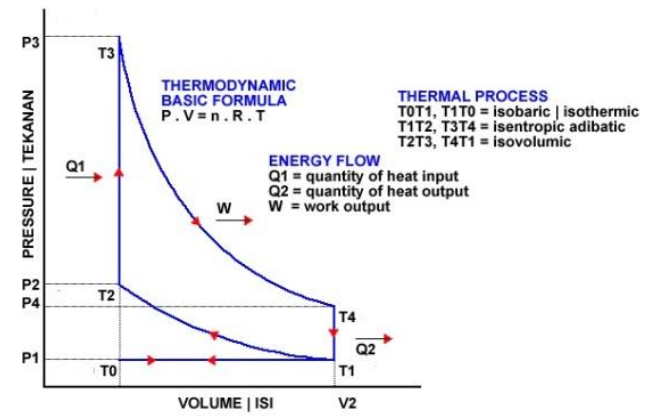

Gambar 2.1 Diagram $P-v$, Siklus Otto (Gasldeal) ${ }^{[2]}$

Prose siklusnya sebagai berikut ${ }^{[2]}$ :

a. Proses $0-1$ (Langkah Hisap) : menghisap udara tekanan konstan, dimana katup masuk terbuka dan katup buang tertutup, piston menghisap udara dan bahan bakar yang telah tercampur kedalam silinder.

$P_{0}=P_{1}$

b. Proses $1-2$ (Kompresi Isentopik): kedua katup tertutup, piston begerak dari TMB ke TMA sehingga meningkat tekanan dan temperatur menjadi $\mathrm{P}_{2}$ dan $\mathrm{T}_{2}$ :

$V_{1}=V_{s}$

$V_{2}=V_{c}$

$\frac{T_{1}}{T_{2}}=\left(\frac{V_{2}}{V_{1}}\right)^{k-1}-\left(\frac{v_{1}}{v_{2}}\right)^{k-1}=r_{C}{ }^{k-1}$

$T_{2}=T_{1} \cdot r_{c}^{k-1}$

$\frac{P_{1}}{P_{2}}=\left(\frac{V_{2}}{V_{1}}\right)^{k}-\left(\frac{v_{1}}{v_{2}}\right)^{k}=r_{C}{ }^{k}$

$P_{2}=P . r_{c}{ }^{k}$

$W_{1-2}=\frac{m_{m} \cdot c_{v}\left(T_{2}-T_{1}\right)}{1-k}$

c. Proses 2 - 3 (pembakaran): penambahan panas volume konstan.

$V_{2}=V_{3}$

$Q_{\text {in }}=m_{m} C_{v}\left(T_{3}-T_{2}\right)=m_{f} \cdot Q_{H V} \cdot n c$

Dimana:

$$
m_{m}=\frac{P_{x} V_{s}}{R \times T}
$$

Dengan adanya rasio kompresi massa udara dan massa fuel dapat dicari seperti persamaan berikut : $m_{f}=\frac{1}{r_{c}+1} \times m_{\text {burn }} \times m_{m}$

dan

$m_{a}=\frac{r_{c}}{r_{c}+1} \times m_{\text {burn }} \times m_{m}$

(sisa hasil pembakaran kisaran 3\% - 7\%, pada tugas akhir ini sisa pembakaran di asumsikan 4\%)

$\frac{P_{3}}{P_{2}}=\left(\frac{T_{3}}{T_{2}}\right)$

$$
P_{3}=P_{2}\left(\frac{T_{3}}{T_{2}}\right)
$$

$\mathrm{T}_{3}=\mathrm{T}_{\max }$ dan $\mathrm{P}_{2}=\mathrm{P}_{\max }$

Proses 3-4 : Expansi isentropik

Tekanan yang membuat piston bergerak ke TMB dan semua katup tertutup.

$V_{1}=V_{4}$

$V_{2}=V_{3}$

$\frac{T_{4}}{T_{3}}=\left(\frac{V_{3}}{V_{4}}\right)^{k-1}=\left(\frac{1}{r_{c}}\right)^{k-1} \Rightarrow T_{4}=T_{3}\left(\frac{1}{r_{c}}\right)^{k-1}$

$\frac{P_{4}}{P_{3}}=\left(\frac{V_{3}}{V_{4}}\right)^{k}=\left(\frac{1}{r_{c}}\right)^{k} \quad \Rightarrow P_{4}=P_{3}\left(\frac{1}{r_{c}}\right)^{k}$

Kerja expansi dari titik 3 ke titik 4 dari siklus otto juga merupakan proses isentopik, persamaannya ditunjukan sebagai berikut :

$W_{3-4}=\frac{m_{m} \cdot R\left(T_{3}-T_{4}\right)}{1-k}$

d. Proses $4-1$ : proses pembuangan sisa pembakaran volume konstan, katup buang terbuka dan katup hisap tertutup.

$Q_{\text {out }}=m_{m} R\left(T_{1}-T_{4}\right)$

Untuk memperoleh kerja netto dalam satu siklus menggunakan persamaan berikut ${ }^{[4]}$ :

$$
W_{\text {net }}=w_{1-2}+w_{3-4}
$$

Dan untuk memperoleh efisiensi termalnya menggunakan persamaan berikut ${ }^{[4]}$ :

$n_{\text {th }}=\frac{W_{\text {net }}}{Q_{\text {in }}}$

Konstanta - konstanta yang berlaku ${ }^{[6]}$ :

$\mathrm{k}$ : Konstanta rasio panas spesifik:

$\mathrm{C}_{\mathrm{P}} / \mathrm{C}_{\mathrm{V}}=1,4$

$\mathrm{C}_{\mathrm{P}}$ : Konstanta panas spesifik pada tekanan konstan : $1,005 \mathrm{~kJ} / \mathrm{kg}$. K

$\mathrm{C}_{\mathrm{V}}$ : Konstanta panas spesifik pada volume konstan : $0,718 \mathrm{~kJ} / \mathrm{kg}$. K

$\mathrm{R}$ : Konstanta udara : 0,287 $\mathrm{kPa}$.

$\mathrm{m}^{3} / \mathrm{kg}$. K : 0,287 kJ/kg. K

$\mathrm{r}_{\mathrm{c}} \quad$ : Rasio kompresi : $v_{1} / v_{2}=v_{4} / v_{3}$ 


\subsubsection{Analisis Perhitungan Performa Mesin}

A. Torsi

$$
T=\frac{\dot{W}_{b}}{2 \pi \cdot N \cdot T}
$$

B. Daya Indikator $\left(\dot{W}_{i}\right)$

$$
\dot{W}_{i}=\left(\frac{W_{\text {net }} \cdot N}{n}\right) \times \mathrm{N}_{\mathrm{c}}
$$

C. Daya Efektif $\left(\dot{W}_{b}\right)$

$$
\dot{W}_{b}=2 \pi \cdot N \cdot T
$$

D. Tekanan Indikator (IMEP)

$$
I M E P=\frac{60,000 \times \dot{W}_{i}}{V_{d} \times \frac{N}{n} \times N_{c}}
$$

E. Tekanan Efektif (BMEP)

$$
B M E P=\frac{60,000 \times \dot{W}_{b}}{V_{d} \times \frac{N}{n} \times N_{c}}
$$

F. Daya Gesek $\left(\dot{W}_{f}\right)$

$$
\dot{W}_{f}=\dot{W}_{i}-\dot{W}_{b}
$$

\subsubsection{Efisiensi Mesin}

Efisiensi Termal Indikator

$\eta_{i}=\frac{\dot{W}_{i}}{\dot{Q}_{\text {in }}} x 100 \%$

Efisiensi Termal Efektif

$\eta_{e}=\frac{\dot{W}_{b}}{\dot{Q}_{\text {in }}} \times 100 \%$

Efisiensi Mekanik

$\eta_{m}=\frac{\dot{W}_{b}}{\dot{W}_{i}} \times 100 \%$

Efisiensi volumetrik

$$
\begin{aligned}
& \rho_{a}=\frac{P}{R \cdot T} \\
& N_{v}=\frac{m_{a}}{\rho_{a} \cdot V_{d}}
\end{aligned}
$$

\subsubsection{Pemakaian Bahan Bakar Spesifik}

Pemakaian Bahan Bakar Indikator (ISFC)

$I S F C=\frac{\dot{m}_{f}}{I H P}$

Dimana : $\dot{m}_{f}=\frac{m_{f} \cdot z \cdot N}{60 \cdot n}$

Pemakaian Bahan Bakar Efektif (BSFC)

$B S F C=\frac{\dot{m}_{f}}{B H P}$

\section{HASIL DAN PEMBAHASAN}

Pembahasan kinerja mesin piston empat tak Lycoming O-540-E4A5 ini akan ditinjau dari beberapa variasi ketinggian terbang (altittude flight variation) dan termasuk di dalamnya variasi kondisi tekanan udara sekitar (ambient air preassure), kecepatan udara (ambient air density) dan temprature udara (ambient air temprature).

\subsection{Perhitungan Geometri Silinder Volume Langkah}

Volume langkah adalah volume pada ketika piston bergerak dari TMA ke TMB.

$\mathrm{B}=5.125 \mathrm{in}=0.130175 \mathrm{~m}$

$S=4.375 \mathrm{in}=0.111125 \mathrm{~m}$

$V_{d}=\left(\frac{\pi}{4}\right) B^{2} . S$

$V_{d}=\left(\frac{3.14}{4}\right) 0.130175^{2} \cdot 0.111125$

$V_{d}=0.001478 \mathrm{~m}^{3}$

Dan $\mathrm{V}_{\mathrm{d}}$ untuk 6 piston adalah $\mathrm{V}_{\mathrm{d}}=$ $0.001478 \times 6=0.008869 \mathrm{~m}^{3}$

Volume Clearance $\left(V_{c}\right)$

Mencari volume pada kondisi piston TMA atau disebut juga Volume Clearance $\left(V_{c}\right)$. Pada data spesifikasi mesin yang dimiliki maka diketahui :

$$
\begin{aligned}
& V_{d}=0.001478 \mathrm{~m}^{3} \\
& r_{c}=8.5
\end{aligned}
$$

Maka perhitungan $V_{c}$ sebagai berikut,

$$
\begin{gathered}
r_{c}=\frac{\left(V_{c}+V_{d}\right)}{V_{c}} \\
=\frac{\left(V_{c}+0.001478\right)}{V_{c}} \\
8.5 V_{c}-V_{c}=0.001478 \\
V_{c}=\frac{0.001478}{7.5} \\
V_{c}=0.000197095 \mathrm{~m}^{3}
\end{gathered}
$$

Dan $\mathrm{V}_{\mathrm{c}}$ untuk 6 piston adalah $\mathrm{V}_{\mathrm{c}}=0.000197095 \times 6=0.001183 \mathrm{~m}^{3}$

Volume cyllinder $\left(V_{s}\right)$ 
Mencari volume total atau disebut juga

Volume Cyllinder $\left(V_{s}\right)$ didapatkan dari manual engine dengan nilai $V_{c}$ sebesar $0.000174 \mathrm{~m}^{3}$ dan $V_{d}$ sebesar 0.001478 $\mathrm{m}^{3}$. Maka perhitungan Volume Cyllinder $\left(V_{s}\right)$ sebagai berikut :

$$
V_{s}=V_{d}+V_{c}
$$

$=0.001478+0.000197095$

$=0.001675 \mathrm{~m}^{3}$

Dan $\mathrm{V}_{\mathrm{c}}$ untuk 6 piston adalah

$$
V_{s}=0.001675 \times 6=0.01005 \mathrm{~m}^{3}
$$

3.2 Perhitungan Pada Ketinggian $10000 \mathrm{ft}$ dan Kecepatan putar rotasional maksimumm di 2700 RPM

Perhitungan kondisi terbang ini dimaksudkan sebagai perhitungan awal yang nanti nya akan dilanjutkan dengan tabel hasil perhitungan disetiap variasi ketinggian.

\subsection{Parameter Kondisi Udara pada Ketinggian Terbang $10000 \mathrm{ft}$}

Parameter kondisi udara pada ketinggian terbang (flight altitude) $10000 \mathrm{ft}$ yaitu :
Temperature -
$: 268.34^{\circ} \mathrm{K}$
Pressure - $P$
: $69.7 \mathrm{kPa}$

\subsection{Analisis Bahan Bakar}

Sebelum melanjutkan ke perhitungan prestasi mesin, akan dianalisis bahan bakar yang akan digunakan terlebih dahulu dan jenis bahan bakar yang dipakai yaitu AVGAS (Aviation Gasoline).

AVGAS memiliki nilai sebagai berikut :

- Heating Value of Fuel - $Q_{H V}: 43500$ $\mathrm{kJ} / \mathrm{kg}$ (Conoco Philips)

- Air Fuel Ratio - AF: 14.7 (nilai standar AF untuk mesin piston)

- Combustion efficiency $\left(\eta_{c}\right)$ yaitu $100 \%$

$$
\begin{aligned}
& \text { Mass of gass mixture }\left(\boldsymbol{m}_{\boldsymbol{m}}\right) \\
& m_{m}=\frac{P_{1} \times V_{s}}{R \times T_{1}}=\frac{69.7 \times 0.001675}{0.287 \times 268.34}=0.001516 \mathrm{~kg}
\end{aligned}
$$

\section{Mass of air $\left(m_{a}\right)$}

$$
\begin{aligned}
& m_{a}=\frac{A F}{A F+1} \times m_{\text {burn }} \times m_{m}= \\
& \frac{14.7}{15.7} \times 0.96 \times 0.001516=0.001362 k
\end{aligned}
$$

Mass of Fuel

$$
\begin{aligned}
m_{f}=\frac{1}{A F+1} \times & m_{\text {burn }} \times m_{m} \\
& =\frac{1}{15.7} \times 0.96 \times 0.001516 \\
& =0.0000927 \mathrm{~kg} / \text { siklus }
\end{aligned}
$$

Mass of exhaust $\left(m_{e x}\right)$

$$
m_{e x}=0.04 \times 0.001516=0.00006064 \mathrm{~kg}
$$

\section{Heat Added}

$$
\begin{aligned}
Q_{\text {in }}=m_{f} \cdot Q_{H V} & \eta_{c} \\
& =0.0000927 \times 43500 \times 1 \\
& =4.03 \mathrm{~kJ}
\end{aligned}
$$

\section{Fuel Flow}

$$
\begin{aligned}
& \dot{m}_{f}=\frac{m_{f} \cdot N_{c} \cdot N}{60 \cdot n}=\frac{0.0000927 \times 6 \times 2700}{60 \times 2}= \\
& 0.0125 \frac{\mathrm{kg}}{\mathrm{sec}}=45.0575 \mathrm{~kg} / \mathrm{hr}
\end{aligned}
$$

Heat Flow Added

$$
\begin{gathered}
\dot{Q}_{i n}=\dot{m}_{f} \cdot Q_{H V} \cdot n c=0.0125 \times 43500 \times 1 \\
=544.445 \mathrm{~kJ} / \mathrm{s}
\end{gathered}
$$

\subsection{Perhitungan Siklus Ideal Otto 4 Tak \\ Perhitungan dari proses siklus otto diperoleh besaran sebagai berikut :}

\section{$>$ Pada proses (0-1) langkah hisap}

Jika dilihat pada siklus 4 Tak $P_{0}=P_{1}$, $T_{0}=T_{1}, V_{1}=V_{s}$

$$
\text { Jadi, } \begin{aligned}
P_{1} & =69.7 \mathrm{kPa} \\
T_{1} & =268.34^{\circ} \mathrm{K} \\
V_{1} & =0.001675 \mathrm{~m}^{3}
\end{aligned}
$$

\section{$>$ Pada proses (1-2) proses kompresi} isentropik

Jika dilihat pada siklus 4 Tak $V_{2}=V_{c}$

Jadi, $V_{2}=0.000197 \mathrm{~m}^{3}$

Menentukan $\boldsymbol{T}_{\mathbf{2}}$

$$
\begin{aligned}
& \frac{T_{2}}{T_{1}}=\left(\frac{V_{1}}{V_{2}}\right)^{k-1} \Rightarrow T_{2} \quad=T_{1}\left(r_{c}\right)^{k-1} \\
& \quad=268.34(8.5)^{1.4-1} \\
& \quad=631.61^{\circ} \mathrm{K}
\end{aligned}
$$

Menentukan $\boldsymbol{P}_{\mathbf{2}}$

$$
\begin{aligned}
\frac{P_{2}}{P_{1}}= & P \cdot r_{c}{ }^{k-1} \Rightarrow P_{2} \quad=P_{1} \cdot r_{c}{ }^{k} \\
& =69.7 \times 8.5^{1.4} \\
& =1394.5024 \mathrm{kPa}
\end{aligned}
$$


Pada proses (2-3) proses panas masuk pada volume konstan

Jika dilihat pada siklus 4 Tak $V_{3}=V_{2}$ Jadi, $V_{3}=0.000197 \mathrm{~m}^{3}$

Menentukan $\boldsymbol{T}_{3}$

$$
\begin{aligned}
& Q_{\text {in }}=m_{m} c_{v}\left(T_{3}-T_{2}\right) \\
& T_{3}=\frac{4.03+(0.001516 \times 0.718 \times 631.61)}{0.001516 \times 0.718} \\
& =4336.1737^{\circ} \mathrm{K}=\mathrm{T}_{\max }
\end{aligned}
$$

Menentukan $\boldsymbol{P}_{3}$

$$
\begin{gathered}
\frac{P_{3}}{P_{2}}=\left(\frac{T_{3}}{T_{2}}\right) \Rightarrow P_{3} \quad=P_{2}\left(\frac{T_{3}}{T_{2}}\right) \\
=1394.5024\left(\frac{4336.1737}{631.31}\right) \\
=9573.549 \mathrm{kPa}
\end{gathered}
$$

$>$ Pada proses (3-4) proses ekspansi isentropik

Jika dilihat pada siklus 4 Tak $V_{4}=V_{S}$ Jadi, $V_{4}=0.001675 \mathrm{~m}^{3}$

Menentukan $\boldsymbol{T}_{\mathbf{4}}$

$$
\begin{aligned}
\frac{T_{4}}{T_{3}}=\left(\frac{V_{3}}{V_{4}}\right)^{k-1}=\left(\frac{1}{r_{c}}\right)^{k-1} & T_{4}=T_{3}\left(\frac{1}{r_{c}}\right)^{k-1} \\
= & 4336.1737\left(\frac{1}{8.5}\right)^{1.4-1} \\
= & 1842.2098^{\circ} \mathrm{K}
\end{aligned}
$$

Menentukan $\boldsymbol{P}_{4}$

$$
\begin{aligned}
& \frac{P_{4}}{P_{3}}=\left(\frac{V_{3}}{V_{4}}\right)^{k}=\left(\frac{1}{r_{c}}\right)^{k} \\
& P_{4}=P_{3}\left(\frac{1}{r_{c}}\right)^{k} \\
& =9573.549\left(\frac{1}{8.5}\right)^{1.4} \\
& =478.504 \mathrm{kPa}
\end{aligned}
$$

$>$ Parameter Siklus Ideal

Menentukan kerja siklus,

- Kerja yang di hasilkan pada saat daya expansi

$$
\begin{aligned}
& W_{3-4}=\frac{m_{m} \cdot R\left(T_{4}-T_{3}\right)}{1-k} \\
& =\frac{0.001516 \times 0.287(1842.2098-4336.1737)}{1-1.4} \\
& =2.71 \mathrm{~kJ}
\end{aligned}
$$

- Kerja yang diserap selama langkah kompresi isentropic

$$
W_{1-2}=\frac{m_{m} \cdot R\left(T_{2}-T_{1}\right)}{1-k}
$$

$=-0.395 \mathrm{~kJ}$

$$
=\frac{0.001516 \times 0.287(631.61-268.34)}{1-1.4}
$$

Maka :

$W_{\text {net }}=W_{1-2}+W_{3-4}=(-0.395)+2.71$

$$
=2.31 \mathrm{~kJ}
$$

Menentukan efisiensi termal dari efisiensi

siklus ideal otto 4 Tak,

$$
\begin{aligned}
n_{\text {th }} & =\frac{W_{\text {net }}}{Q_{\text {in }}} \times 100 \% \\
= & \frac{2.31}{4.03} \times 100 \% \\
= & 0,5747 \times 100 \% \\
& =57.47 \%
\end{aligned}
$$

\subsection{Perhitungan Daya Mesin}

$>\quad$ Indicated Horse Power $\left(\dot{W}_{i}\right)$

$\dot{W}_{i}=\left(\frac{W_{\text {net }} . N}{n}\right) N_{c}$

$$
\begin{aligned}
& =\left(\frac{2.31 \times 2700}{60 \times 2}\right) \times 6 \\
& =312.9214 \mathrm{~kW} \rightarrow 425.4547 \mathrm{HP}
\end{aligned}
$$

$>\quad$ Brake Horse Power $\left(\dot{W}_{b}\right)$

Untuk mencari nilai Brake Horse Power dapat menggunakan grafik hubungan antara BHP dan Pressure Altitude sehingga didapat nilai sebesar $182 \mathrm{BHP}$ $182 \mathrm{BHP}=135717.385 \mathrm{Nm} / \mathrm{s}$ $182 B H P=135.717 \mathrm{~kW}$

Torsi (T)

$\dot{W}_{b}=2 \pi . N . T$

$$
\begin{aligned}
135717.385 & =2 \pi \times \frac{2700}{60} \times T \\
T & =\frac{135717.385}{2 \pi \frac{2700}{60}}
\end{aligned}
$$

$$
=480.24 \mathrm{Nm}
$$

\section{(IMEP)}

$$
\begin{aligned}
& \text { IMEP }=\frac{60.000 \times \dot{W}_{i}}{V_{d} \cdot n \cdot N_{c}} \\
&= \frac{60.000 \times 312.9214}{0.001478 \times \frac{2700}{2} \times 6} \\
&= 1568068.063 \frac{\mathrm{N}}{\mathrm{m}^{2}} \\
& \rightarrow 227.4294 \mathrm{psi}
\end{aligned}
$$

\section{$>$ Break Mean Effective Pressure (BMEP)}

$$
\begin{array}{r}
B M E P=\frac{60.000 \times \dot{W}_{i}}{V_{d} \cdot n \cdot N_{c}} \\
=\frac{60.000 \times 133.86}{0.001478 \times \frac{2700}{2} \times 6}
\end{array}
$$




$$
=670784.4017 \frac{\mathrm{N}}{\mathrm{m}^{2}} \rightarrow 97.289 \mathrm{psi}
$$

$>$ Friction Horse Power $\left(\dot{W}_{f}\right)$

$$
\dot{W}_{f}=\dot{W}_{i}-\dot{W}_{b}
$$

$=425.4547-182$

$=243.4547 \mathrm{HP}$

$>$ Indicated Speciefic Fuel

Consumption (ISFC)

$$
\begin{aligned}
\text { ISFC } & =\frac{\dot{m}_{f}}{\dot{W}_{i}} \\
& =\frac{45.0575}{425.4547}=0.105 \mathrm{~kg} / \mathrm{hr} / \mathrm{HP}
\end{aligned}
$$

$>$ Break Speciefic Fuel Consmption (BSFC)

$$
\begin{aligned}
B S F C & =\frac{\dot{m}_{f}}{\dot{W}_{b}} \\
& =\frac{45.0575}{182} \\
& =0.24 \mathrm{~kg} / \mathrm{hr} / \mathrm{HP}
\end{aligned}
$$

\subsection{Perhitungan Efisiensi Mesin}

\section{> Efisiensi Termal Indikator}

$$
\begin{aligned}
& \eta_{i}=\frac{\dot{W}_{i}}{\dot{Q}_{i n}} \times 100 \%=\frac{312.9214}{544.445} \times 100 \% \\
& =0.5747 \times 100 \% \\
& =57.47 \%
\end{aligned}
$$

$>$ Efisiensi Termal Efektif

$$
\begin{aligned}
\eta_{e} & =\frac{\dot{W}_{b}}{\dot{Q}_{i n}} \times 100 \% \\
& =\frac{133.86}{544.445} \times 100 \% \\
& =0.2458 \times 100 \% \\
& =24.58 \%
\end{aligned}
$$

$>$ Efisiensi Mekanik

$$
\begin{aligned}
\eta_{m} & =\frac{\dot{W}_{b}}{\dot{W}_{i}} \times 100 \% \\
& =\frac{182}{425.4547} \times 100 \% \\
& =0.4277 \times 100 \% \\
& =42.77 \%
\end{aligned}
$$

$>$ Efisiensi volumetrik

$$
\begin{aligned}
& \rho_{a=\frac{p_{1}}{R \cdot T_{1}}} \\
& =\frac{69.7}{0.287 \times 268.34} \\
& =0.9050 \mathrm{~kg} / \mathrm{m}^{3}
\end{aligned}
$$

Maka dapat dicari Efisiensi volumetrik sebagai berikut :

$$
N_{v}=\frac{m_{a}}{\rho_{a} \cdot V_{d}}
$$

$=\frac{0.001362}{0.9050 \times 0.001478} \times 100 \%=101 \%$

Dengan cara dan perhitungan yang sama maka juga dilakuan untuk ketinggian terbang $15.000 \mathrm{ft}$ dan 20.000 $\mathrm{ft}$. Berikut adalah hasil perhitungan kondisi gas ideal dari siklus otto :

Tabel 4.1 Hasil Perhitungan Temperature, Pressure, dan Volume udara pada Ketinggian $10000 \mathrm{ft}$

\begin{tabular}{|r|r|r|r|}
\hline Proses & $\mathbf{T}^{\mathbf{}} \mathbf{K}$ & $\mathbf{P}(\mathbf{k P a}$ & $\mathbf{V} \mathbf{( m}^{\mathbf{3}} \mathbf{)}$ \\
\hline Titik 1 & 268.34 & 69.7 & 0.001675 \\
\hline Titik 2 & 631.61 & 1394.50 & 0.000197 \\
\hline Titik 3 & 4336.17 & 9573.54 & 0.000197 \\
\hline Titik 4 & 1842.20 & 478.50 & 0.001675 \\
\hline
\end{tabular}

Tabel 4.2 Hasil Perhitungan Temperature, Pressure, dan Volume udara pada Ketinggian $15000 \mathrm{ft}$

\begin{tabular}{|r|r|r|r|}
\hline Proses & $\mathbf{T}^{\mathbf{}} \mathbf{K}$ & $\mathbf{P}(\mathbf{k P a}$ & $\left.\mathbf{V} \mathbf{( m}^{\mathbf{3}}\right)$ \\
\hline Titik 1 & 258.43 & 57.2 & 0.001675 \\
\hline Titik 2 & 608.28 & 1144.41 & 0.000197 \\
\hline Titik 3 & 4312.84 & 8114.02 & 0.000197 \\
\hline Titik 4 & 1832.29 & 405.55 & 0.001675 \\
\hline
\end{tabular}

Tabel 4.3 Hasil Perhitungan Temperature, Pressure, dan Volume udara pada Ketinggian $20000 \mathrm{ft}$

\begin{tabular}{|r|r|r|r|}
\hline Proses & $\mathbf{T}^{\mathbf{}} \mathbf{K}$ & $\mathbf{P}(\mathbf{k P a}$ & $\mathbf{V} \mathbf{( m}^{\mathbf{3}} \mathbf{)}$ \\
\hline Titik 1 & 248.56 & 46.6 & 0.001675 \\
\hline Titik 2 & 585.05 & 930.33 & 0.000197 \\
\hline Titik 3 & 4289.61 & 6835.84 & 0.000197 \\
\hline Titik 4 & 1822.42 & 341.66 & 0.001675 \\
\hline
\end{tabular}

Pada Tabel 4.1, Tabel 4.2 dan Tabel 4.3 dapat dilihat pada titik 1 atau proses hisap (suction) udara di atmosfer masuk ke dalam sistem pada temperature dan pressure berdasarkan dari ketinggian terbang yang ada di tabel ISA (International Standard Atmosphere $)^{[6]}$, pada titik 2 atau proses kompresi isentropik, volume silinder dalam sistem mengecil sehingga temperature dan pressure meningkat, pada titik 3 atau proses ekspansi isentropic, terjadi proses pembakaran bahan bakar sehingga temperature dan pressure meningkat secara signifikan dan pada titik 4 atau 
proses pembuangan pada volume konstan terjadi pembuangan gas hasil pembakaran sehingga temperature dan pressure mengalami penurunan. Pola ini memang sama dengan kecenderungan yang didapat oleh persamaan siklus Otto, namun karena ada variasi ketinggian terbang pesawat maka nilai tertinggi dari setiap proses yang diwakilkan dalam fungsi titik yaitu adalah diketinggian $10.000 \mathrm{ft}$.

Tabel 4. 4 Torsi

\begin{tabular}{|r|r|}
\hline Ketinggian & Torsi \\
\hline $10000 \mathrm{ft}$ & $480.24 \mathrm{Nm}$ \\
\hline $15000 \mathrm{ft}$ & $395.806 \mathrm{Nm}$ \\
\hline $20000 \mathrm{ft}$ & $319.284 \mathrm{Nm}$ \\
\hline
\end{tabular}

Nilai Torsi pada Tabel $\mathbf{4 . 4}$ merupakan nilai yang didapat dari persamaan Brake Horse Power $\left(\dot{W}_{b}\right)$ melalui grafik hubungan antara BHP vs Pressure Altitude [5]

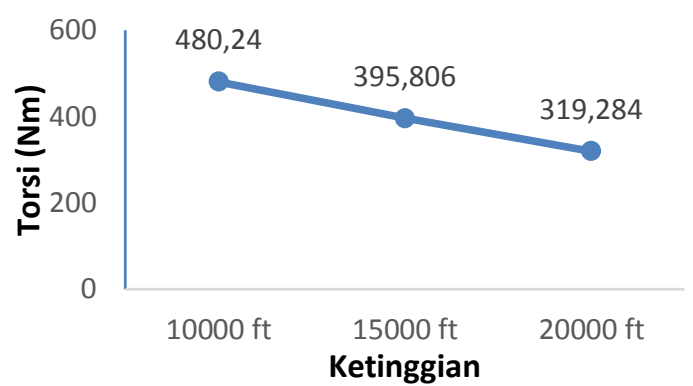

Gambar 4. 1 Grafik torsi pada variasi ketinggian

Dari Gambar 4.1 dapat dilihat nilai torsi turun seiring kenaikan ketinggian, dari ketinggian $10.000 \mathrm{ft}, 15.000 \mathrm{ft}$ dan $20.000 \mathrm{ft}$ secara berturut-turut nilainya adalah $480.28 \mathrm{Nm}, 395,806 \mathrm{Nm}$ dan $319.284 \mathrm{Nm}$

Tabel 4. 5 Daya mesin

\begin{tabular}{|r|r|r|r|}
\hline Ketinggian & $\dot{\boldsymbol{W}}_{\boldsymbol{i}}$ (watt) & $\dot{\boldsymbol{W}}_{\boldsymbol{b}}$ (watt) & $\dot{\boldsymbol{W}}_{\boldsymbol{f}}$ (watt) \\
\hline $10000 \mathrm{ft}$ & 425.45 & 182 & 243.45 \\
\hline $15000 \mathrm{ft}$ & 362.54 & 150 & 212.54 \\
\hline $20000 \mathrm{ft}$ & 307.08 & 121 & 186.08 \\
\hline
\end{tabular}

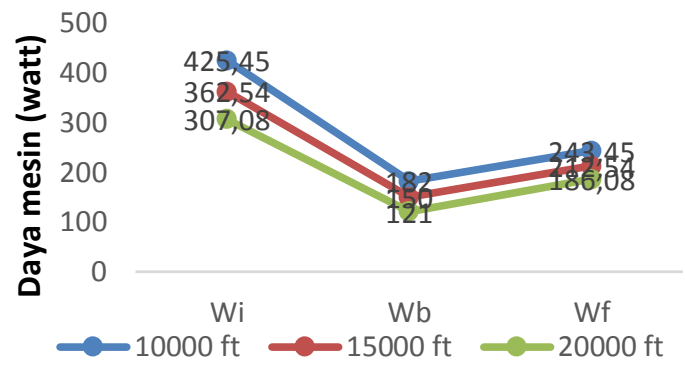

Gambar 4. 2 Daya Mesin pada variasi ketinggian

Dari Gambar 4.2 dapat di lihat daya mesin terbagi atas $\dot{W}_{i}, \dot{W}_{b}$ dan $\dot{W}_{f}$ dari ketiga jenis daya mesin tersebut diketinggian $10.000 \mathrm{ft}$ memilki nilai daya mesin tertinggi yaitu 425.45 watt untuk $\dot{W}_{i}$ , 182 watt untuk $\dot{W}_{b}$ dan 243.45 watt untuk $\dot{W}_{f}$.

Tabel 4.6 Efisiensi Mesin

\begin{tabular}{|r|l|l|l|l|}
\hline Ketinggian & $\boldsymbol{\eta}_{\boldsymbol{i}}$ & $\boldsymbol{\eta}_{\boldsymbol{e}}$ & $\boldsymbol{\eta}_{\boldsymbol{m}}$ & $\boldsymbol{\eta}_{\boldsymbol{V}}$ \\
\hline $10000 \mathrm{ft}$ & $57.47 \%$ & $24.58 \%$ & $42.77 \%$ & $101 \%$ \\
\hline $15000 \mathrm{ft}$ & $57.47 \%$ & $23.78 \%$ & $41.37 \%$ & $101 \%$ \\
\hline $20000 \mathrm{ft}$ & $57.47 \%$ & $22.64 \%$ & $39.40 \%$ & $101 \%$ \\
\hline
\end{tabular}

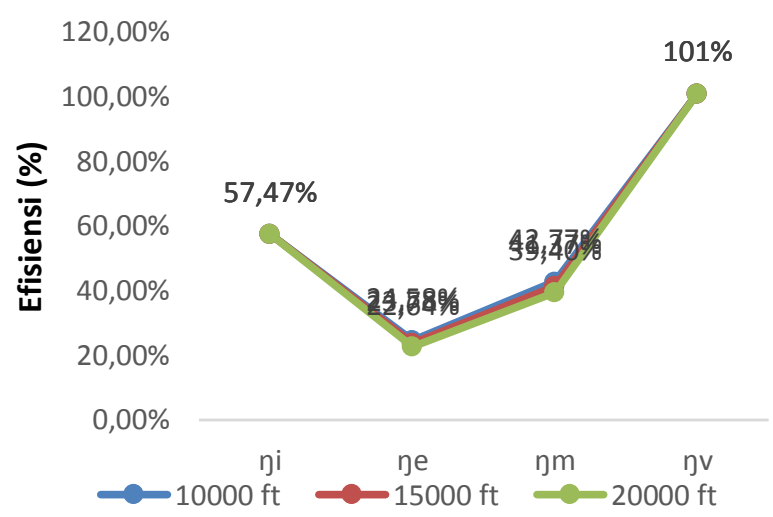

Gambar 4. 3 Efisiensi Mesin pada variasi ketinggian

Dari Gambar 4.4 dapat dilihat efisiensi mesin pada termal indikator $\left(\dot{W}_{l}\right)$ tidak mengalami perubahan untuk setiap 
variasi ketinggian karena kerja dan panas yang dimasukkan ada dalam kondisi gas ideal, sedangkan untuk efisiensi thermal efektif dan efisiensi mekanik mengalami penurunan akibat nilai brake horse power makin turun seiring dengan kenaikan ketinggian. Sedangkan volume efficiency yang terjadi pada engine sempurna.

\section{KESIMPULAN}

Berdasarkandari hasil analisis perhitungan dan pembahasan, maka dapat diambil beberapa kesimpulan berikut ini :

- Mesin Lycoming O-540-E4A5 mengalami penurunan performa di setiap peningkatan ketinggian di karenakan menurunnya nilai tekanan dan temperatur pada saat proses hisap (suction) pada siklus engine.

- Nilai torsi, daya mesin dan efesiensi mesin mekanik tertinggi terjadi pada ketinggian $10.000 \mathrm{ft}$, dengan nilai torsi $=480.24 \mathrm{Nm}$, daya mesin $=182 \mathrm{HP}$ dan nilai efesiensi mekanik $=42.77 \%$.

\section{DAFTAR PUSTAKA}

1. Pulkrabek., W., W., 1997, Engineering Fundamentals Of The Internal Combustion Engine, Prentice Hall, New Jersey.

2. El-Sayed., A., F., 2006, Aircraft Propulsion And Gas Turbine Engines, CRC Press, Florida.

3. Ganesan., V., 2012, Internal Combustion Engines, Edisi 3, The McGraw - Hill Companies, New Delhi.

4. Rizal., M., S., 2013, Konversi Energi, Cimahi

5. Approved by FAA, June 2006, Operator's Manual Lycoming o-540, IO-540 Series

6. NASA, 1976, U.S Standard Atmosphere, Washington DC. 